\title{
Renewable energy powered membrane technology: Computational fluid dynamics evaluation of system performance with variable module size and fluctuating energy
}

\author{
Cristina Onorato $^{\mathrm{a}}$, Maximillian Gaedtke ${ }^{\mathrm{a}, \mathrm{b}}$, Michael Kespe ${ }^{\mathrm{b}}$, Hermann Nirschl $^{\mathrm{b}}$, \\ Andrea I. Schäfer ${ }^{\mathrm{a}, *}$ \\ ${ }^{a}$ Membrane Technology Department, Institute of Functional Interfaces (IFG-MT), Karlsruhe Institute of Technology (KIT), Hermann-von-Helmholtz-Platz 1, 76344 \\ Eggenstein-Leopoldshafen, Germany \\ ${ }^{\mathrm{b}}$ Institute for Mechanical Process Engineering and Mechanics (MVM), Karlsruhe Institute of Technology (KIT), Straße am Forum 8, 76131 Karlsruhe, Germany
}

\begin{abstract}
A B S T R A C T
Renewable energy powered membrane systems operate with fluctuating energy. Such fluctuations affect pressure and feed flow and as such the hydrodynamic conditions in a membrane system. Hydrodynamic variations alter the membrane surface concentration and boundary layer thickness which in turn determines permeate water quality. In this work this is calculated using computational fluid dynamics (CFD) for the three most predominant energy levels obtained during such fluctuations and compared with experimental data.

A 2D-CFD simulation was performed using OpenFOAM to calculate the wall concentration and boundary layer thickness over the length of a module. The influence of module type was investigated using two system configurations, namely three 2.5" modules in series (BW30-2540 or NF270-2540) and one 4" module (BW304040 and NF270-4040) with similar total membrane areas. Energy levels were extracted from experimental data at three solar irradiance, maximum intensity $\left(1 \mathrm{~kW} / \mathrm{m}^{2}\right)$, light cloud $\left(360 \mathrm{~W} / \mathrm{m}^{2}\right)$ and heavy cloud periods $\left(190 \mathrm{~W} / \mathrm{m}^{2}\right)$

At the highest energy level, in the system with three $2.5^{\prime \prime}$ modules the wall concentration was closer to the bulk concentration due to the higher flow velocity in a smaller channel. The resulting boundary layer thickness for BW30 was constant and almost zero. At the medium energy level, the simulation results show that the permeate flux decreased significantly due to the lower pressure and for the BW30 it was almost zero due to the low pressure. At the lowest energy level, the feed pressure was well below the osmotic pressure and no permeation was possible.

Results from this study show that the model is able to describe the filtration process in spiral wound membrane modules under fluctuating energy conditions. Further investigations on the possibility to improve the boundary conditions of the model are required.
\end{abstract}

\section{Introduction}

Drinking water provision in remote locations where the access to natural freshwater sources are limited or non existent is one of the main issues to be faced in this century [1]. Furthermore, the supply of fresh water requires energy and many countries in the world that lack freshwater sources are also deficient in energy sources. As a matter of fact, more than 1.3 billion people worldwide still lack access to elec tricity, with more than $95 \%$ of them located in sub Saharan Africa and developing Asia, and 1 billion people are connected to an unreliable electric grid $[2,3]$. Water and energy are interdependent since water is needed for the production of energy (for example, in hydroelectric, nuclear, and thermal power plants) while energy is required for the production of clean, drinkable water (for example, through processes such as desalination where heat or pressure is the driving force). De salination technologies show great potential to solve water availability challenges. Through coupling with renewable energy sources, such as photovoltaics or wind turbines, the energy demand of such technologies can be managed in a sustainable manner $[3,4]$.

Reverse osmosis (RO) and nanofiltration (NF) are considered among the best available technologies for water treatment when dissolved contaminants such as ions are to be removed. Spiral wound modules 
(SWM) are the most common commercially available membrane mod ules [5 7]. These technologies can be directly coupled with solar en ergy, providing the power for the pump, therefore the energy input is directly dependent on the daytime solar irradiation [8,9]. Such varia tion affects pressure and feed flow of operation and hence the perfor mance of the membranes in terms of water permeation and permeate quality.

Renewable energy powered RO and NF technologies have been studied intensely in recent years from both the theoretical and experi mental point of view $[1,10,11]$. The focus of this research is on the theoretical investigations, which are then used to explain experimental observations [12].

Several semi analytical models have been developed in order to investigate the effect of important parameters such as the concentration polarization (CP) phenomena [13]. Geraldes et al. [14] have developed a numerical model to describe solute mass flux based on solution dif fusion, while a correction was used to deal with the osmotic pressure variation. In order to understand retention mechanisms in $\mathrm{NF} / \mathrm{RO}$, knowledge of the wall concentration is essential. However, carrying out such calculations in complex geometries as the membrane channel, and in particular during fluctuating conditions, is a challenge [15]. Nu merical flow simulations have been increasingly used in recent years for modelling complex flow patterns in membrane systems because they provide a more precise approach by including several parameters in the model development. Wardeh and Morven further developed the ap proach of Geraldes et al. using simulations software 'ANSYS CFX' to simulate a membrane channel with membranes on both upper and lower side [16]. Gruber et al. (2011) integrated this approach into 'OpenFOAM' and further validated [17].

Computational fluid dynamics (CFD) has been used predominantly for investigating the influence of different flow regimes on concentra tion polarization and fouling control [18,19]. Several studies were carried out to optimize the membrane module design, in particular, the spacer configuration and orientation [10,20,21]. From these studies it was concluded that the zigzag spacer is the most efficient for the SWM $[16,19,22]$. Fimbres Weihs and Wiley [23] have reviewed the topic of CFD with a focus on spacer design, including the case of permeable walls, thoroughly. In another review, applied to desalination, Krabelas et al. (2015) have continued with a further review on spacer design and pointed out the importance of the permeate fabric in performance and spacer design in potential membrane damage. Most importantly 'it is very likely that there is no single set of "optimum" SWM design parameter values' meaning that the ideal design may well be application depen dent [23]. To actually determine the flow conditions under fluctuating energy is very complex and, to date, there are no reports of CFD modelling works of SWM in fluctuating energy conditions. However, Dimitriou et al. [24] developed and implemented a mathematical model in the MATLAB environment in order to predict the performance (such as permeate flow and quality) of a membrane element in non constant operating conditions (pressure and flow rate). This research is set in this context, and the main aims of this research are to;

(i) develop a CFD model for calculating the wall concentration ( $\left.\mathrm{c}_{\text {wall }}\right)$ and boundary layer thickness $\left(\delta_{\mathrm{c}}\right)$ over the length of a SWM at three different energy levels that are typical in energy fluctuations,

(ii) determine the impact of this wall concentration and boundary layer thickness on permeate quality,

(iii) investigate the influence of module size using two system config urations (namely $3 * 2.5^{\prime \prime}$ modules in series and $1 * 4$ " module) on the process performance under energy fluctuation, and, ultimately,

(iv) compare the CFD simulation results with real experimental data in order to clarify the role of the module configuration and therefore of the wall concentration (concentration polarization) on permeate quality.

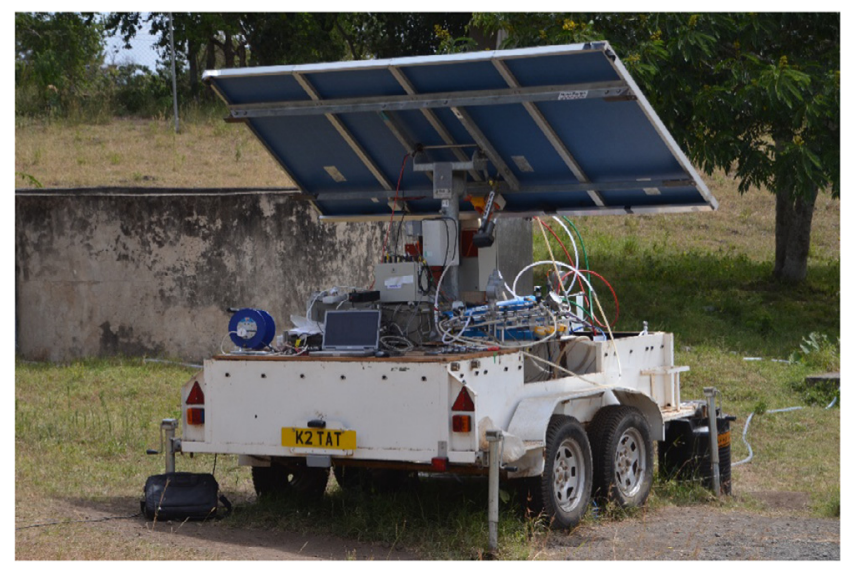

Fig. 1. Solar powered NF/RO system used to obtain the experimental data used in this study.

\section{Experimental data}

Experimental data, detailed methodology and water quality analysis on which this simulation study is based is published elsewhere [12]. In summary, a solar powered NF/RO system shown in Fig. 1 was used to desalinate brackish water in Tanzania. This system was developed by Richards and Schäfer and many reports of experimental data have been published $[1,11,25]$.

Given that the experimental study was carried out with 5 different membranes, for the purpose of the simulation two membranes were selected, namely NF270, as the most open NF membrane, and BW30, as a tighter brackish water RO membrane. With this choice the range of conditions in terms of permeability and retention was covered. The membrane modules used are summarized in Table 1.

The fluctuation of solar irradiance of a typical solar day is shown in Fig. 2. This data was prepared and supplied to the system with a solar array simulator in order to achieve reproducible irradiation input. The fluctuations in irradiance were the basis for the selection of three op eration points for the simulations, namely (i) full power at maximum solar irradiance $\left(1000 \mathrm{~kW} / \mathrm{m}^{2}\right)$, (ii) medium level fluctuation (360 W/ $\mathrm{m}^{2}$ ) referred to as 'light cloud period', and (iii) low level fluctuation $\left(190 \mathrm{~kW} / \mathrm{m}^{2}\right)$ referred to as 'heavy cloud period' were performed.

To simplify the retention of the many contaminants measured ex perimentally, the simulation was performed via the sum parameter TDS. The feed TDS of the water used from Mdori, Tanzania was cal culated as $4205.7 \mathrm{mg} / \mathrm{L}$. The corresponding feed osmotic pressure was calculated using the van't Hoff equation to be 2.88 bar at $25^{\circ} \mathrm{C}$. Further correlation of TDS concentration and osmotic pressure was performed using the relationship in Eq. (1) for this particular brackish water.

$$
\pi=685.4 \cdot 10^{5} \mathrm{~Pa} \cdot \mathrm{c}
$$

For the model this TDS was further simplified as $6.25 \mathrm{~g} / \mathrm{kg} \mathrm{NaCl}$ as the main input parameter to the model. Further operational parameters will be detailed in the model validation section. A WTW Multi 340i instrument was used to determine $\mathrm{pH}$ and electrical conductivity.

\section{Model development}

The model described in this paper is based on the open source toolkit OpenFOAM (Open Field Operation and Manipulation) $[10,19,20,26]$. The implementation of the model has been performed in two steps (i) implementation of the solver for the governing equation and (ii) implementation of proper boundary condition at the membrane surface. Validation of the model was carried out using (i) real experi mental data and (ii) data provided by the manufacturer of the mem branes tested "Dow Chemical Company" (DOW). Manufacturer soft ware 'Reverse Osmosis System Analysis' (ROSA) Version 9.1 was used 
Table 1

Membrane module types and dimensions (all Dow Chemicals).

\begin{tabular}{llll}
\hline Membrane & Module diameter $\mathrm{d}_{\text {module }}$ (") & Module length $\mathrm{l}_{\text {module }}$ (") & Membrane area $\mathrm{A}_{\text {module }}$ (m ${ }^{2}$ ) \\
\hline Filmtech NF270 & 2.5 & 40 & 2.6 \\
& 4.0 & 40 & 7.6 \\
Filmtech BW30 & 2.5 & 40 & 2.6 \\
& 4.0 & 40 & 7.2 \\
\hline
\end{tabular}

to validate the implementation of the solution diffusion model in OpenFOAM.

\subsection{Governing equations}

The flow in the membrane channel is governed by equations for conservation of mass and momentum (known as Navier Stokes equa tions) and convection diffusion transport equation for the solute mass fraction [23]. These are partial differential equations which have an analytical solution only for simple cases. For solving these equations in case of general flows involving complex geometries and complex boundary conditions, numerical methods as CFD are used [23].

The governing equations implemented in the model are:

$\frac{\partial \rho}{\partial t}+\nabla \cdot(\rho \boldsymbol{U})=0$

$\frac{\partial \rho \boldsymbol{U}}{\partial t}+\nabla \cdot(\rho \boldsymbol{U} \boldsymbol{U})=\nabla \cdot\left[\mu\left(\nabla \boldsymbol{U}+\nabla \boldsymbol{U}^{T}\right)\right]-\nabla p+\rho \mathbf{g}$

$\frac{\partial \rho m_{A}}{\partial t}+\nabla \cdot\left(\rho \boldsymbol{U} m_{A}\right)-\nabla \cdot\left(\rho D_{A B} \nabla m_{A}\right)=0$

where $\rho$ is the fluid density $\left(\mathrm{kg} \mathrm{m}^{-3}\right)$, $\mathbf{U}$ the fluid velocity vector $\left(\mathrm{m} \mathrm{s}^{-1}\right), \mathbf{g}$ the gravitational acceleration $\left(\mathrm{m} \mathrm{s}^{-2}\right), \mathrm{m}_{\mathrm{A}}$ the solute mass fraction $\left(\mathrm{kg} \mathrm{kg}^{-1}\right)$ and $\mathrm{D}_{\mathrm{AB}}$ is the solute diffusion coefficient $\left(\mathrm{m}^{2} \mathrm{~s}^{-1}\right)$.

Published studies $[27,28]$ have shown that neither gravity nor density variation have a significant effect on the solution obtained. Therefore in the CFD modelling, constant density and no gravity effects are assumed. Moreover, the fluid is typically assumed to be Newtonian with constant physical properties and the flow is assumed to be iso thermal [23]. The flow is assumed to be laminar, according to what is typical in real membrane systems [10].

\subsection{Solution diffusion model and boundary conditions}

Conservation equations do not describe the transport through the membrane, which requires additional relations. Since a complete

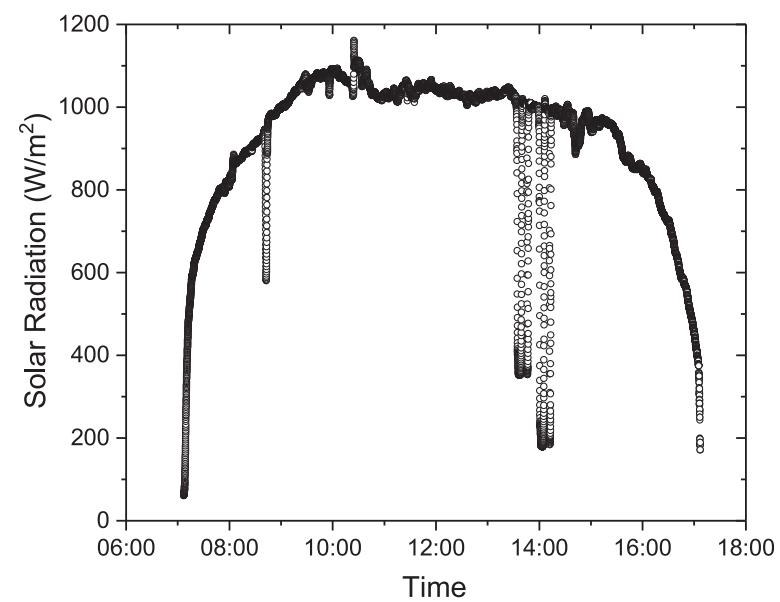

physical description of the transport process through the membrane involves many dependencies and interactions [29], a simplified model namely the 'Solution diffusion model' described by Merten et al. [30] has been used. The solution diffusion model is the most widely accepted description of water and solute fluxes for RO membranes [21,29,31,32]. The basic premise of the solution diffusion model is that the permeating species dissolve into the membrane material and molecularly diffuse through it as a consequence of a concentration gradient. The solution diffusion model assumes that the pressure within the membrane is constant at the high pressure value and the chemical potential of feed and permeate fluids are in equilibrium with the adjacent membrane surface [29]. The simplified process, resulting in concentration polar ization, is shown in Fig. 3, while the model itself is reviewed in detail elsewhere [29]. Feed flows parallel to the membrane surface and the transmembrane pressure (applied pressure minus osmotic pressure) results in a permeate flux, which is the permeate flow normalized with the membrane area. In the process a boundary layer with a thickness $\delta_{c}$ and a concentration $\mathrm{c}_{\mathrm{W}}$ at the membrane surface establishes, which is referred to as concentration polarization.

Summarizing and simplifying the solution diffusion model, water $\left(\mathrm{J}_{\mathrm{i}}\right)$ and solute flux $\left(\mathrm{J}_{\mathrm{j}}\right)$ can be described with Eqn. (5) and (6), respec tively

$\dot{J}_{i}=A \cdot(\Delta p-\Delta \pi)$

where $\mathrm{A}$ is the solvent, or water permeability constant, $\Delta \mathrm{p}$ is the pres sure difference and $\Delta \pi$ the osmotic pressure differential across the membrane.

$\dot{J}_{j}=B \cdot\left(c_{j 0}-c_{j l}\right)$

where B is the solute, or salt permeability constant, $c_{j 0}$ the feed con centration and $c_{j 1}$ the concentration in the membrane at the permeate interface [29].

Constants A and B can be determined experimentally, while despite various simplifications these equations were shown to be sufficiently precise for brackish or seawaters [29].

The solution diffusion equations are not suitable for use and

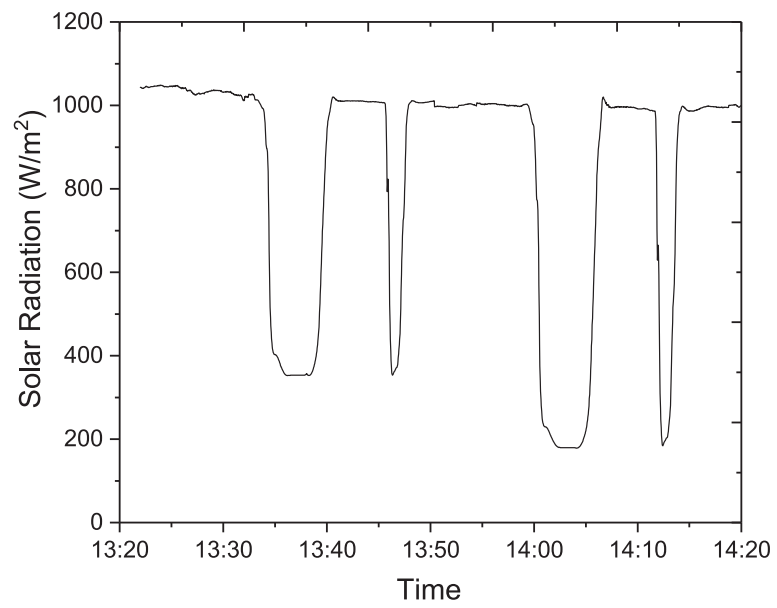

Fig. 2. Solar irradiance (A) over the course of a daytime and (B) the fluctuation from maximum irradiance (full power) to medium irradiance (light cloud) and lowlevel irradiance (heavy cloud) [25]. 


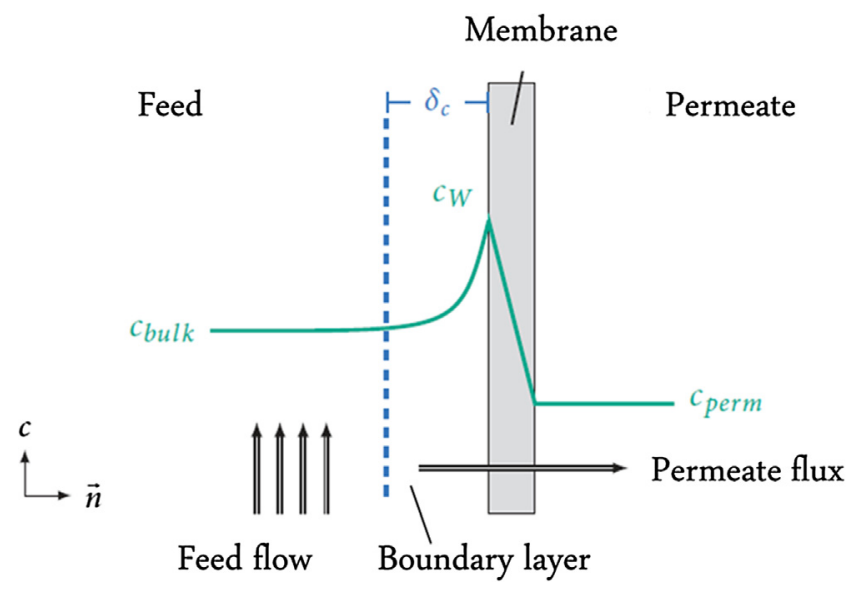

Fig. 3. Concentration polarization in crossflow filtration: feed flow, permeate flux, boundary layer and wall concentration.

boundary conditions for velocity and concentration need to be im plemented, in order to reduce the unknown variables. The boundary condition used in this work is the 'permeable wall case' in which the membrane is assumed as permeable [23]. The water flux through the membrane is calculated according to the solution diffusion transport mechanism where the permeation is caused by a pressure difference between the feed and the permeate channels [16]. The permeate mass flow is perpendicular to the membrane surface, the fluid velocity normal to the wall is obtained from the permeate flux by dividing Eqn. (5) by the water density;

$u_{n}=k \cdot(\Delta p-\Delta \pi)$

where $\mathrm{k}$ is a constant based on the permeate flux of pure solvent. If the pressure on the permeate side is assumed to be zero, then the pressure difference across the membrane will be equal to the feed pressure;

$\Delta p=p_{\text {feed }}-p_{\text {ermeate }}=p_{\text {feed }}$

Convective and diffusive fluxes must be balanced on both sides of the membrane. Taking into account that not all salts permeate through the membrane, the rejection of salt is considered and defined as $[10,16,20,21,26]$. This is used to determine the permeate concentra tion.

$R=\left(1-\frac{c_{j l}}{c_{j 0}}\right)$

As such the transport the mass balance at the membrane surface consists of the equilibrium of convection and diffusion (based on Fick's law) as the boundary condition of the concentration at the membrane surface [10].

$\rho_{i} c_{i} u_{n} R+\rho D_{A B} \cdot \frac{\partial c}{\partial n}=0$

Eq. (10) does not include a possible permeate flux from the permeate side to the feed side. Indeed in a typical steady state reverse osmosis process, this flux can be neglected compared to the main permeate flux, although this case may not be correct during fluctua tions.

The integration of these equations into OpenFOAM is available. A consideration of the impact of permeate side transport was neglected in the current work, as was the possibility to allow a negative permeate flux.

\subsection{Fluid and membrane parameters}

Viscosity, diffusion coefficient, density and osmotic pressure are assumed to be a function of the salt concentration, based on empirical expressions for the physical properties of $\mathrm{NaCl}$ at $25^{\circ} \mathrm{C}[10,16,26]$.

$\pi=\pi_{0} \cdot 10^{5} m_{A}(\mathrm{inPa})$

where $m_{A}$ is the solute mass fraction $\left(\mathrm{kg} \mathrm{kg}^{-1}\right), \pi$ is the osmotic pres sure (Pa), with $\pi_{0}=805.1$ for $\mathrm{NaCl}$ Solutions, and $\pi_{0}=648.1$ for the specific Tanzania brackish water used in the experimental study and as described above. The dynamic viscosity $\mu$ (Pa.s) of salty aqueous solu tions up to a mass fraction of $0.9 \mathrm{~kg} / \mathrm{kg}$ [14] is described as a function of mass fraction in Eq. (12),

$\mu=0.89 \cdot 10^{-3} \cdot\left(1+1.63 \cdot m_{A}\right)$

and the fluid density $\rho\left(\mathrm{kg} \mathrm{m}^{-3}\right)$ for the same solution in Eqn. (13)

$\rho=997.1+694 \cdot m_{A}$

While the diffusion coefficient of the solute $\mathrm{D}_{\mathrm{AB}}\left(\mathrm{m}^{2} \mathrm{~s}^{-1}\right)$ was de termined based on measurements of Poisson and Papaud [33], which is based on seawater rather than pure $\mathrm{NaCl}$ at a temperature of $25^{\circ} \mathrm{C}$, which appears suitable for this research.

$D_{A B}=\max \left(1.61 \cdot 10^{-9}\left(1-14 \cdot m_{A}\right), 1.44 \cdot 10^{-9}\right.$

In order to compare the results of this simulation with experimental data [34] the concentration value of $4206 \mathrm{mg} / \mathrm{L}$ of the brackish water from Tanzania was used ( $\mathrm{pH}(9.7)$ and the conductivity $(4940 \mu \mathrm{S} / \mathrm{cm}))$. The conductivity was converted in TDS using Eq. (15) [35];

$T D S=k \cdot E C$

where TDS is the total dissolved solids concentration ( $\left.\mathrm{mg} \mathrm{L}^{-1}\right)$, and EC the electrical conductivity $\left(\mu \mathrm{S} \mathrm{cm}^{-1}\right)$. The conversion of Singh and Kalra was used to adapt water quality and conductivity measurements [36]. This results in Eq. (1) above, allowing to calculate osmotic pres sure as a function of concentration.

\subsection{Geometry and grid generation}

In order to simulate the flow in spiral wound membrane, a suitable computational grid has to be created. The analysed geometry is the zigzag spacer arrangement [37]. This geometry has been selected be cause it is similar to the spacer geometry used in the real spiral wound modules and it presents better performance in terms of mass transfer and pressure loss characteristic than other configurations [6,16]. Fig. 4 shows a section in the axial direction of the spiral wound with an al ternating arrangement of the spacers on both sides of the feed channel. If unrolled, such a channel corresponds to a $2 \mathrm{D}$ channel used in simu lations [38].

Fimbres Wehs et al. [6] have shown that this simplified geometry described the real flow in a spiral wound membrane with a sufficient approximation. Some geometrical parameters were suggested and these have been implemented in this work as it is shown in Table 2.

For the simulation, it was assumed that the fluid flowing out of the computing area, is the input fluid of the next computing area. This enabled to map the entire length $\left(l_{\text {Modul }}=0.96 \mathrm{~m}\right)$ with a small, iden tically repeating section of the module over the simulation time. This was required to reduce simulation effort. In the simulation, inputs $(\partial \Omega \mathrm{E})$ and outputs $(\partial \Omega \mathrm{A})$ of the geometry were periodically linked. With the program "createPatch", available in OpenFOAM the edges of the geometry were coupled from output to input.

A computational grid, corresponding to the geometry, was gener ated (Fig. 5) with the help of the Open Source software 'gmsh' [39]. From all parameters, wall concentration was found to be the parameter most dependent on the mesh density and was consequently selected to compare different meshes with a different number of nodes. The con ventional procedure in a grid independence study was used to perform consecutive simulations with an increasing number of grid points until a grid independent result was obtained. A wide number of mesh points were generated and the 89,310 mesh points at a channel length of $5.6 \mathrm{~mm}$ gave the lowest relative error of $5.6 \%$ in wall concentration, 


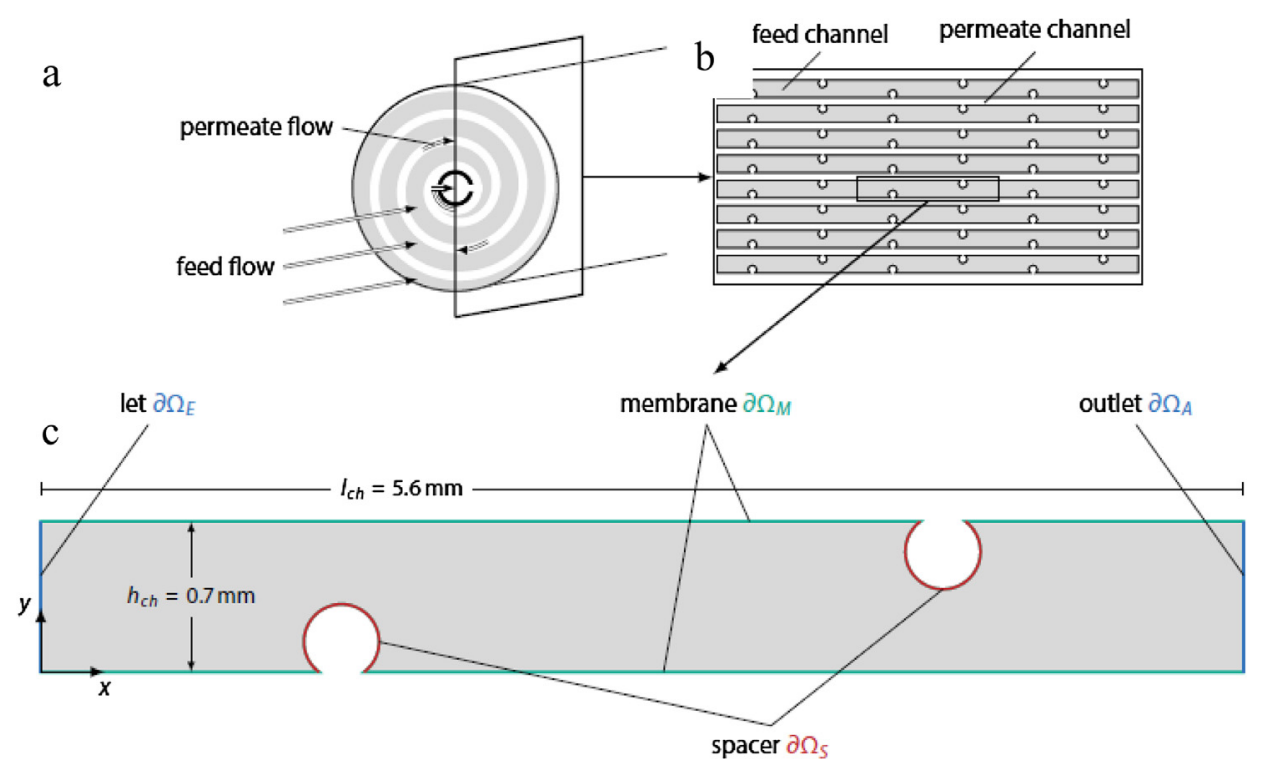

Fig. 4. (a) Schematic representation of the membrane pocket of a spiral wound module with the feed channel in grey and the permeate channel in white. (b) Schematic sectional view in the axial direction through the module with alternately arranged spacers. (c) Schematic representation of the raking area with the parameters $h_{c h}, l_{c h}$ and $d_{s p}$ for the description of the geometric conditions.

Table 2

Geometrical parameters implemented in the model $\left(h_{c h}\right.$, $l_{c h}, d_{s p}$ are the channel height, length and the spacer diameter, respectively $(\mathrm{mm}))$.

\begin{tabular}{ll}
\hline Parameter & Value \\
\hline $\mathrm{h}_{\mathrm{ch}}$ & $0.7 \mathrm{~mm}$ \\
$\mathrm{l}_{\mathrm{ch}}$ & $8 \cdot \mathrm{h}_{\mathrm{ch}}=5.6 \mathrm{~mm}$ \\
$\mathrm{~d}_{\mathrm{sp}}$ & $0.5 \cdot \mathrm{h}_{\mathrm{ch}}=0.35 \mathrm{~mm}$ \\
\hline
\end{tabular}

compared to the maximum of 546,550 mesh points with a $0 \%$ error. This mesh was therefore used for the simulation, outweighing efficiency and tolerable error. The actual code is available in the work of Gaedtke [40].

Subsequently the unstructured mesh was created using the algo rithms 'MeshAdapt' and 'Delaunay'. A structured mesh was not used, while the spacers were implemented in that these materials were in tegrated with an increased density.

The implementation of Neumann and Dirichlet boundary conditions for the pressure was not possible for the periodic linking of input and output areas (Fig. 6), therefore an alternative procedure was required. OpenFOAM offers the option to fix a pressure reference point at which the pressure can be kept constant. The pressure reference point $P_{\text {Ref }}$ was placed in the centre $(2.8 \mathrm{~mm}, 0.35 \mathrm{~mm})$ of the area for the geometry used in this work. The pressure was assumed to be constant through the module because, in the periodic boundary conditions, the pressure on the two sides of the geometry was considered as equal. Therefore the calculated pressure loss in one computing area could not be transferred to the next one and the pressure was overwritten for each time step. This is a shortfall that has to be considered in future work, as the pressure loss over the length of a module is of course not negligible.

In the case of periodically linked boundary conditions, the model takes into account the change in the flow rate in each computational area due to the permeate flow through the membrane. This results in a reduced velocity after each time step. A decrease of the mean velocity ūfrom the starting value $\mathrm{u}_{0}=0.11 \mathrm{~m} \mathrm{~s}^{-1}$ tou $=0.109 \mathrm{~m} / \mathrm{s}$ after a si mulation time of $\mathrm{t}=0.1 \mathrm{~s}$ has been obtained. The decrease in speed corresponded to the 'collected' permeate mass of $1.00 \mu \mathrm{g}$.

Fig. 7 shows the simulated velocity field for the time step $t=0.1 \mathrm{~s}$ and Fig. 8 shows the concentration field of this simulation. Both figures show three connected simulation domains and a detailed view shows the interface between the first and second raking areas in order to il lustrate the continuity.

The spacers caused the formation of large recirculation region be hind the filaments, as expected. The concentration boundary layer next to the spacer was disturbed by the flow. In the region behind the fila ment, a low velocity and then a boundary layer has been detected.

\subsection{Numerical solution}

The OpenFOAM Solver 'twoLiquidMixingFoam' offers the possibility to use a combination of 'SIMPLE' (the semi implicit method for pres sure linked equations) and 'PISO' (pressure implicit split operator) al gorithms. This combination is known as 'PIMPLE' algorithm [41] and is

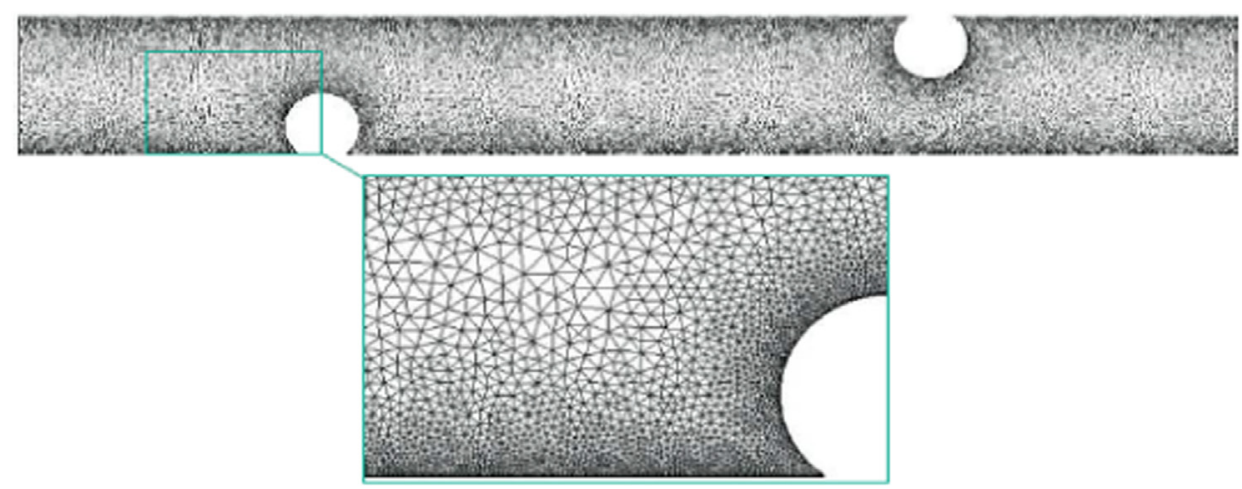

Fig. 5. Representation of the unstructured lattice with a detailed representation of the densification of the lattice points on the membranes and spacers. 


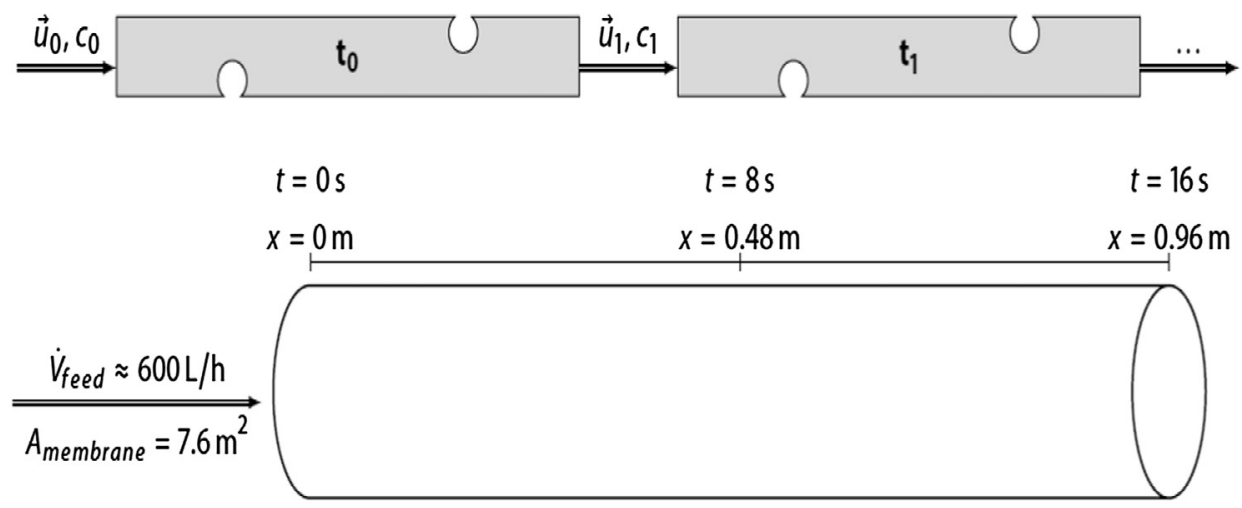

Fig. 6. Periodically linked geometry. Simulation time t corresponds to a position $\mathrm{x}$ in the module.

used to solve the Navier Stokes equations that describe continuity as well as three special dimensions of velocity.

'SIMPLE' is developed for the steady state condition to reach that state very fast but (normally), does not contain time derivation and therefore no time information. Using the 'PISO' mode this is corrected and the time step is limited. This means that it is very expensive to solve a real time problem in a transient manner for a long time especially in very complex geometries.

An experimental series of six simulations have shown that for the model of this work, the settings nCorrectors $=2$ and nOuterCorrectors $=3$ represent a suitable compromise between stabi lity and speed of the solution.

Another method often used in OpenFOAM is the 'relaxationFactors' $(\alpha)$ which controls under relaxation, a technique used for improving the stability of a computation, particularly in solving steady state pro blems. Under relaxation works by limiting the increment of a variable from one iteration to the next, as is shown in Eqn. (16) and (17) [42].

$\mathrm{p}^{\text {new }}=\alpha_{\mathrm{p}} \cdot \mathrm{p}+\left(1-\alpha_{\mathrm{p}}\right) \cdot \mathrm{p}^{\text {old }}$

$\mathrm{u}_{\mathrm{i}}^{\text {new }}=\alpha_{\mathrm{u}} \cdot \mathrm{u}_{\mathrm{i}}+\left(1-\alpha_{\mathrm{u}}\right) \cdot \mathrm{u}_{\mathrm{i}}^{\text {old }}$

A test series of four simulations gave a stable and fast solution for $\alpha=0.8$ for both pressure and velocity equation. In order to guarantee temporal accuracy and numerical stability, a Courant number, Co [43], of less than 1 is required. The Courant number can be defined as the ratio between the time step and the cell size in the velocity direction. The time step $\Delta \mathrm{t}$ was determined to fix the value Comax $=0.9$. A series of tests of 13 simulations with the developed model yielded a set of optimized settings [40]. By adopting the mechanisms implemented by OpenFOAM, a speed advantage of $31.4 \%$ could be achieved for the test simulation. The simulation of a complete flow through the module with the length $l_{\text {Modul }}=0.96 \mathrm{~m}$ could thus be reduced to about $30 \mathrm{~h}$. The high performance 'HP XC3000' simulations were performed on the high performance computer 'HP XC3000' (Steinbuch Center for Com puting (SCC)) of the Karlsruhe Institute of Technology (KIT). The computational grid was split with the 'Scotch' method into 32 processor cores and the simulation was calculated in parallel. A split of more than 32 processor cores did not provide an additional speed advantage.

In the post processing of the results data, relevant quantities were calculated using custom applications developed with OpenFOAM li braries. The 'Runtime Postprocessing' function has been used to register some data during the runtime of the simulation. The recorded para meters are time (s), distance $(\mathrm{m})$ covered by the fluid in the $\mathrm{x}$ direction of the membrane module, fluid velocity $\left(\mathrm{m} \mathrm{s}^{-1}\right)$, pressure drop $\left(\mathrm{Pa} \mathrm{m}^{-1}\right)$, permeate concentration (concentrations in the simulations have taken the form of mass fraction) $\left(\mathrm{kg} \mathrm{kg}^{-1}\right)$, concentrate con centration $\left(\mathrm{kg} \mathrm{kg}^{-1}\right)$, wall concentration $\left(\mathrm{kg} \mathrm{kg}^{-1}\right)$ and permeate flux $\left(\mathrm{kg} \mathrm{m}^{-2} \mathrm{~s}^{-1}\right)$ or permeate flux LMH $\left(\mathrm{L} \mathrm{m}^{-2} \mathrm{~h}^{-1}\right)$.

The boundary layer thickness is by definition the distance from the membrane surface where the concentration assumes the value of $1 / 0.99$ of the bulk concentration, hence the wall concentration can be defined as Eq. (18);

$c\left(\delta_{c}\right)=\frac{1}{0.99} \cdot \bar{c}$

The above calculations are carried out only in sections where such values are required, to reduce excessive demands on calculation time. The schematic representation of the numerical determination of the boundary layer thickness is shown in Fig. 9. The width of the boundary layer is calculated in the simulation at the lower right corner of the flow domain, where the concentration between the cells is interpolated lin early. 'faceIndexHigher' is the cell where the salt concentration is just over the average concentration divided by 0.99 , which 'fa ceIndexLower' is the point just under.

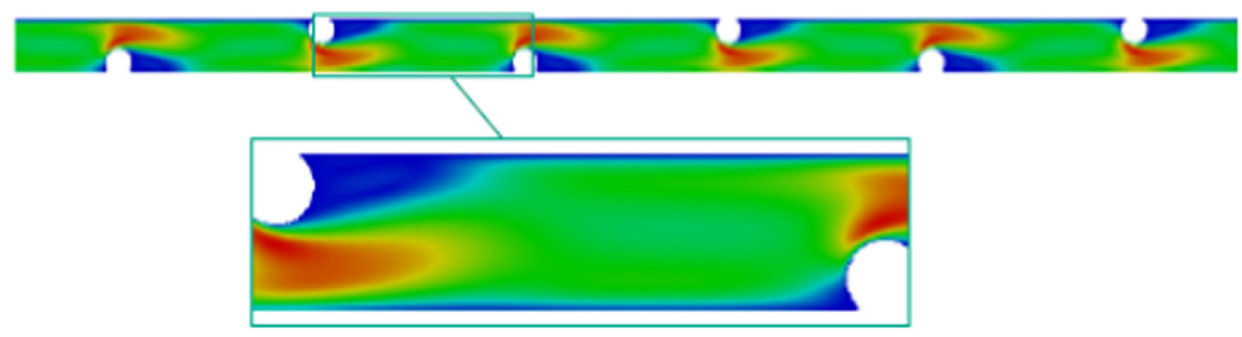

$\mathrm{u}$ in $\mathrm{m} / \mathrm{s}$

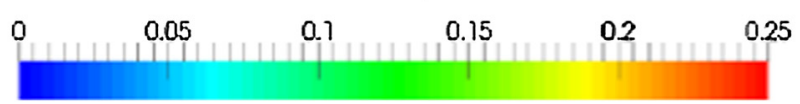

Fig. 7. Simulated velocity field for a feed velocity of $\mathrm{u}_{\mathrm{Feed}}=0.11 \mathrm{~m} / \mathrm{s}$ and a feed concentration of $\mathrm{c}_{\mathrm{Feed}}=6.25 \mathrm{~g} \mathrm{~kg}^{-1}$ with three periodically connected computation areas with detailed representation of the interface. 


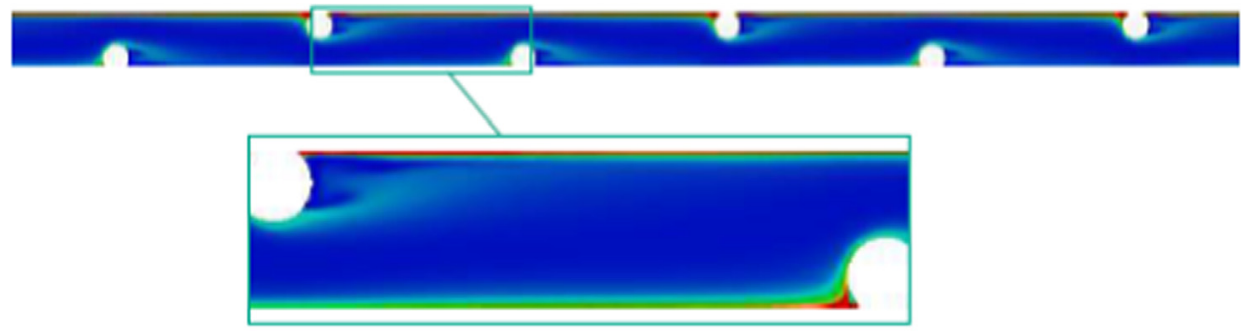

$c$ in $g / k g$

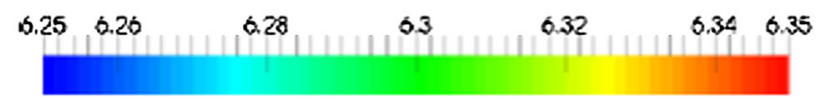

Fig. 8. Simulated concentration field for a feed rate of $\mathrm{u}_{\mathrm{Feed}}=0.11 \mathrm{~m} / \mathrm{s}$ and a feed concentration of $\mathrm{c}_{\mathrm{Feed}}=6.25 \mathrm{~g} \mathrm{~kg}{ }^{-1}$ with three periodically connected simulation domains with detailed representation of the close point.

\subsection{Model validation}

In order to validate the model, the results of the simulation were compared to the data derived from a software called 'Reverse Osmosis System Analysis (ROSA)' provided by the membrane manufacturer, DOW chemical company.

$\mathrm{NaCl}$ solutions with concentrations of $3.5,6.25,9 \mathrm{~g} / \mathrm{kg}$, pressures of $1,3.75,6.50 \mathrm{bar}$ and a flow velocity of $0.11 \mathrm{~m} / \mathrm{s}$ were used. The properties of two nanofiltration membranes (NF270 and BW30) were simulated with ROSA and OpenFOAM and compared. Fig. 10 shows the relation between permeate flux and pressure.

For the simulation of the permeate flux, the pure water permeability $\mathrm{k}\left(\mathrm{L} \mathrm{m}^{-2} \mathrm{~h}^{-1} \mathrm{bar}^{-1}\right)$ was required. In order to show the influence of the parameter $\mathrm{k}$ on the result of the simulation, different values $(4.40,1.97$, 3.50 for BW30 and 16.20, 14.86, 5.10 for NF270) have been tested in accordance with the literature $[34,44,45]$. Fig. 10(a) shows that the model is able to represent the dependency between permeate flux and feed pressure.

Since the respective average values of permeability correspond best to the results obtained with ROSA for the BW30 as well as the NF270 membrane (Fig. 10(a)), the values $\mathrm{k}_{\mathrm{BW} 30}=3.29 \pm 1.00\left(\mathrm{~L} \mathrm{~m}^{-2} \mathrm{~h}^{-1} \mathrm{bar}^{-1}\right.$ ) and $\mathrm{k}_{\mathrm{NF} 270}=12.5 \pm 4.95\left(\mathrm{~L} \mathrm{~m}^{-2} \mathrm{~h}^{-1} \mathrm{bar}^{-1}\right)$ are used for the simulations. The relative deviation was calculated using Eq. (19);
$f_{j}=\frac{J_{O P e n F O A M}-J_{R O S A}}{J_{R O S A}}$

The permeate flux values of the OpenFOAM simulation show an average relative deviation from the values of the ROSA data of $21.5 \%$ for both membranes, although the deviation is far greater for the more open NF270 membrane that the tighter BW30. The mass flow of the dissolved substance through the membrane is a function of the con centration on the surface of the membrane (Eq. (19)), which in turn depends on rejection, which can be calculated from feed and permeate concentrations.

Permeate concentration is calculated as a second verification stage, using three different feed concentrations of $3.50 \mathrm{~g} \mathrm{~kg}^{-1}, 6.25 \mathrm{~g} \mathrm{~kg}^{-1}$ and $9.00 \mathrm{~g} \mathrm{~kg}^{-1} \mathrm{NaCl}$. The feed pressure and the velocity were kept constant at $\mathrm{p}=3.75$ bar and $\mathrm{u}_{\mathrm{Feed}}=0.11 \mathrm{~m} / \mathrm{s}$. These values correspond to the average operating conditions of the filtration plant from Tanzania. Fig. 10(b) shows that the simulation results agree with the ROSA results. The relative deviation was calculated as given in Eq. (20);

$f_{c}=\frac{c_{\text {perm }, \text { OpenFOAM }}-c_{\text {perm }, \text { ROSA }}}{c_{\text {perm }, \text { ROSA }}}$

The permeate concentrations of the OpenFOAM simulation show an average relative deviation from the ROSA data sets of only $1.6 \%$ for
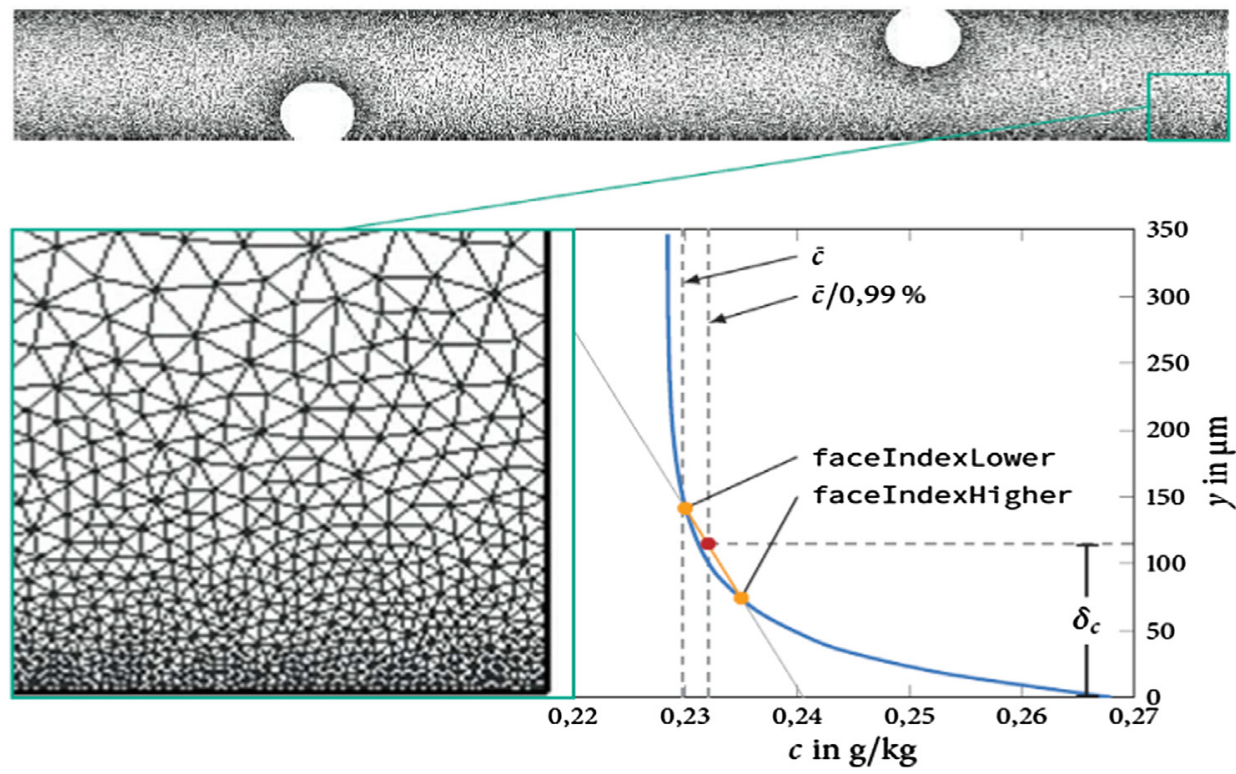

Fig. 9. Schematic representation of the numerical determination of the boundary layer thickness at the output of the computational area between the two values 'faceIndexHigher' and 'faceIndexLower'. 

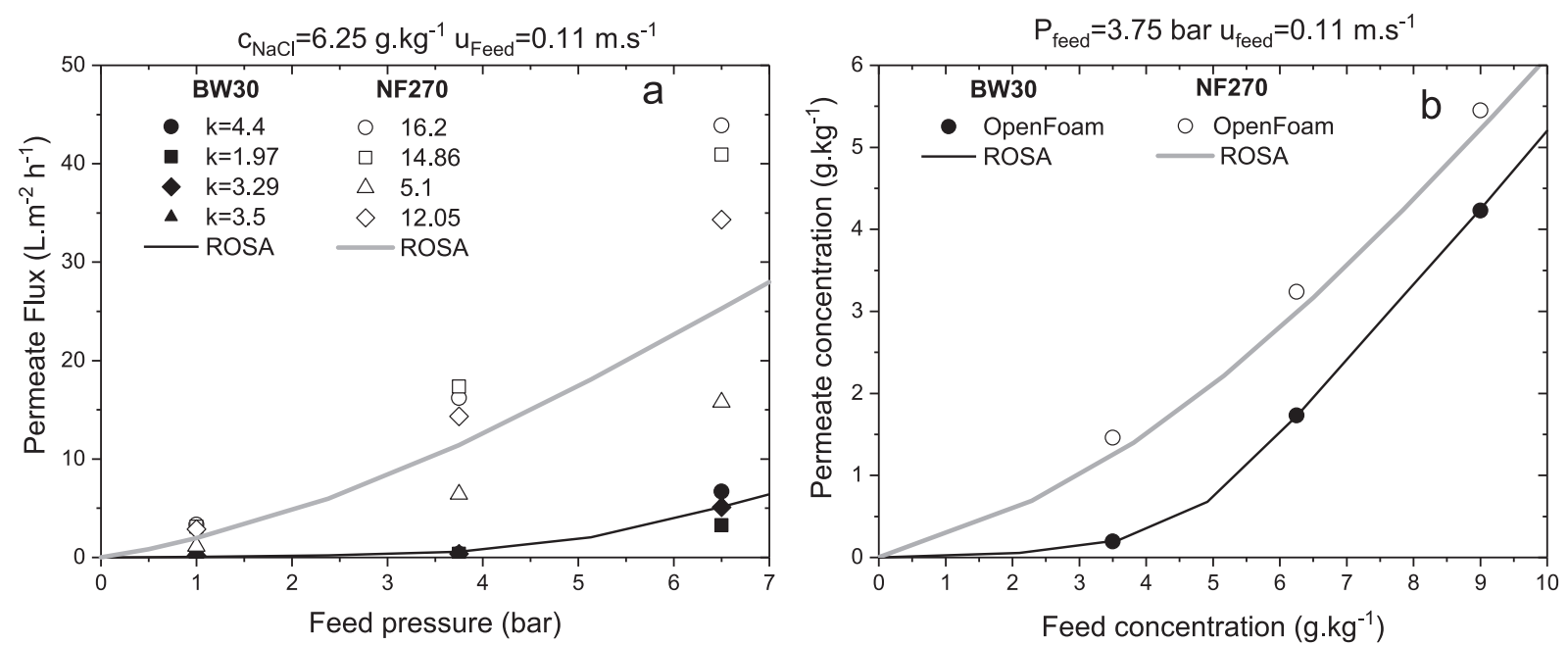

Fig. 10. (a) Relation between permeate flux and pressure for two membranes BW30 and NF270 at a feed concentration of $\mathrm{c}=6.25 \mathrm{~g} / \mathrm{kg}$ NaCl; (b) relation between feed concentration and permeate concentration at feed pressure of $\mathrm{p}=3.75$ bar and a feed flow velocity $\mathrm{uFeed}=0.11 \mathrm{~m} \mathrm{~s}{ }^{-1}$.

both membranes. The model will now be used to calculate the wall concentrations at the different irradiance, and hence power, levels.

\section{Comparison of CFD model with experimental data}

In order to determine the wall concentration over the length of the modules, three different simulations, with the two membranes and two module configurations at three different energy levels namely (i) full power at maximum solar irradiance $\left(1000 \mathrm{~kW} / \mathrm{m}^{2}\right)$, (ii) medium level fluctuation $\left(360 \mathrm{~W} / \mathrm{m}^{2}\right)$, and (iii) low level fluctuation $\left(190 \mathrm{~kW} / \mathrm{m}^{2}\right)$ were performed. These energy levels were shown in Fig. 2.

\subsection{Maximum energy level (maximum solar irradiance of $1000 \mathrm{~kW} / \mathrm{m}^{2}$ )}

The maximum energy level is achieved when the sun has the highest intensity, which is the period from about 10 to $16.00 \mathrm{~h}$ in Fig. 2 . Figs. 11 and 12 show the simulated values for the different membrane module configurations, for BW30 and NF270, respectively. Fig. 11(a) shows the results for 1 * BW30 4040 (over a length of $1 \mathrm{~m}$ ) and (b) the 3 * BW30 2540 in series (over a length of $3 \mathrm{~m}$ ), at the highest energy level $\left(1 \mathrm{kWh}^{-1}, 532610 \mathrm{Lh}^{-1}\right.$ and $\left.5.46 .8 \mathrm{bar}\right)$.

As expected Fig. 11 shows that the permeate flux $\mathrm{J}$ decreases over the length of the module for both configurations due to the increasing concentration in the feed channel, which is evident from the increase in the concentrate concentration. In fact, both bulk and wall concentration increases over the length of the module. In the system with $3 * 2.5^{\prime \prime}$ modules, the wall concentration was closer to the bulk concentration due to the higher flow velocity in a smaller channel. At approximately the same volumetric flow $\left(570 \mathrm{~L} \mathrm{~h}^{-1}\right)$, the feed velocity of the $1 * 4^{\prime \prime}$ and the $3 * 2.5^{\prime \prime}$ modules was $0.061 \mathrm{~m} / \mathrm{s}$ and $0.162 \mathrm{~m} \mathrm{~s}^{-1}$ respectively. In deed the wall concentration is about $1 \%$ above the bulk concentration over the length of the $2.5^{\prime \prime}$ module; in the case of the 4 " module, it is $2.5 \%$ above.

The permeate concentration is very low, given the high rejection of the BW30 membrane. Notably different is the boundary layer thickness that is about $10 \mu \mathrm{m}$ in the case of the single 4" module, while in the case of the boundary layer is $<1 \mu \mathrm{m}$, which is effectively the only notable difference in these results. The results are in agreement with the ex perimental data, where a reduction of the flux has been registered from the first to the last of the three modules in series [12].

Fig. 11(a) shows that the boundary layer thickness $(\delta)$ increases in the inlet region, at $7 \mathrm{~cm}$ it achieves a maximum and then $\delta$ starts to decrease due to the reduction of the concentration gradient. For the $3 * 2.5^{\prime \prime}$ module $\delta$ is fairly constant, if not absent altogether. The permeate concentration $\left(c_{p}\right)$ is very low and fairly constant for both configurations over the length of the module. For the $1 * 4$ " module the calculated value is $0.10 \mathrm{~g} \mathrm{~kg}^{-1}$ and $7 \%$ lower than the experimental value. For the $3 * 2.5^{\prime \prime}$ modules it results in $0.06 \mathrm{~g} \mathrm{~kg}^{-1}$ and about $5 \%$
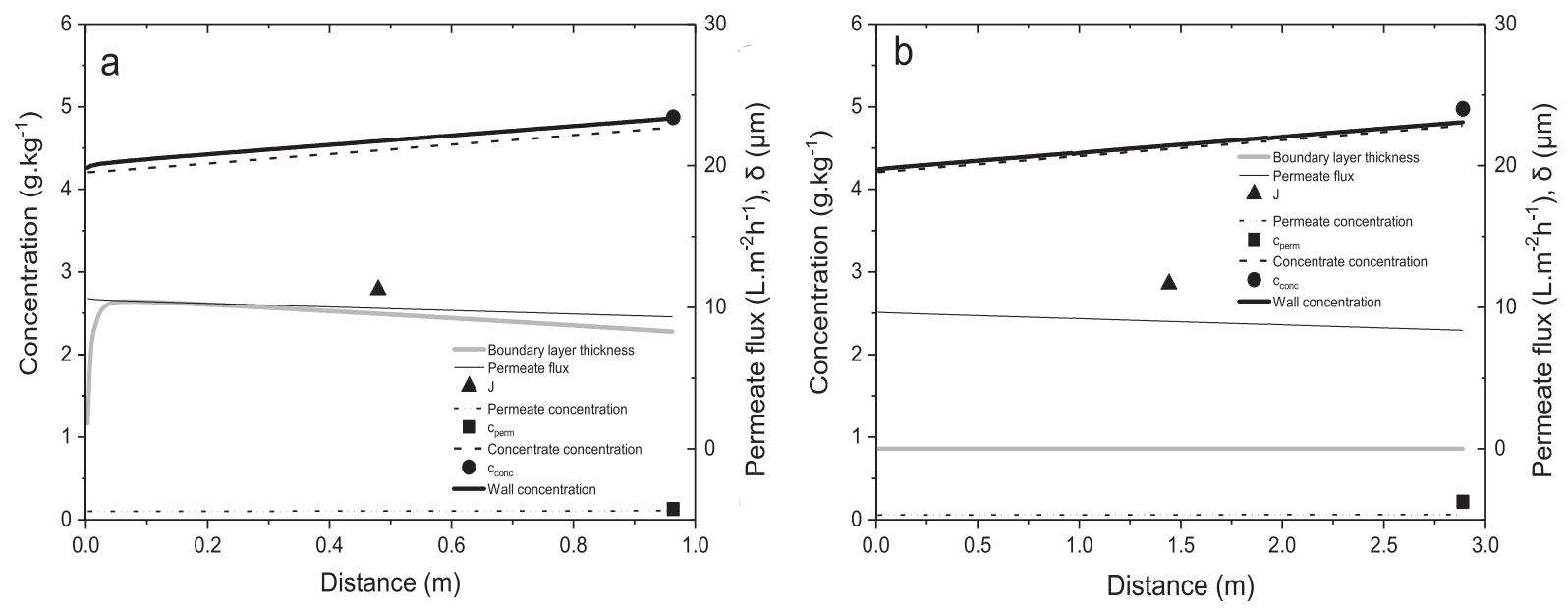

Fig. 11. Trend of the wall, permeate and concentrate concentration, permeate flux and boundary layer thickness over the length of the module for the (a) $1 *$ BW304040 and (b) $3 *$ BW30-2540 configurations at the highest energy level. 

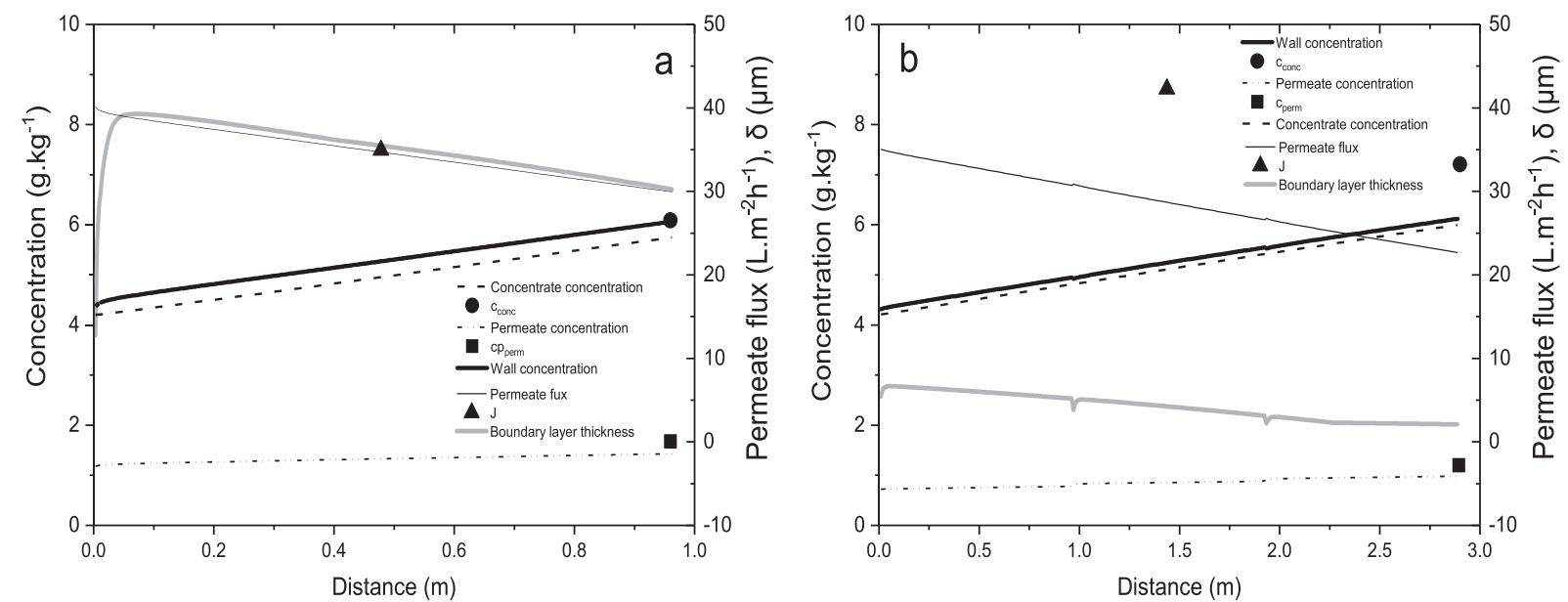

Fig. 12. Trend of the wall, permeate and concentrate concentration, permeate flux and boundary layer thickness over the length of the module for the (a) 1 * NF2704040 module and (b) $3^{*}$ NF270-2540 configurations at the highest energy level.
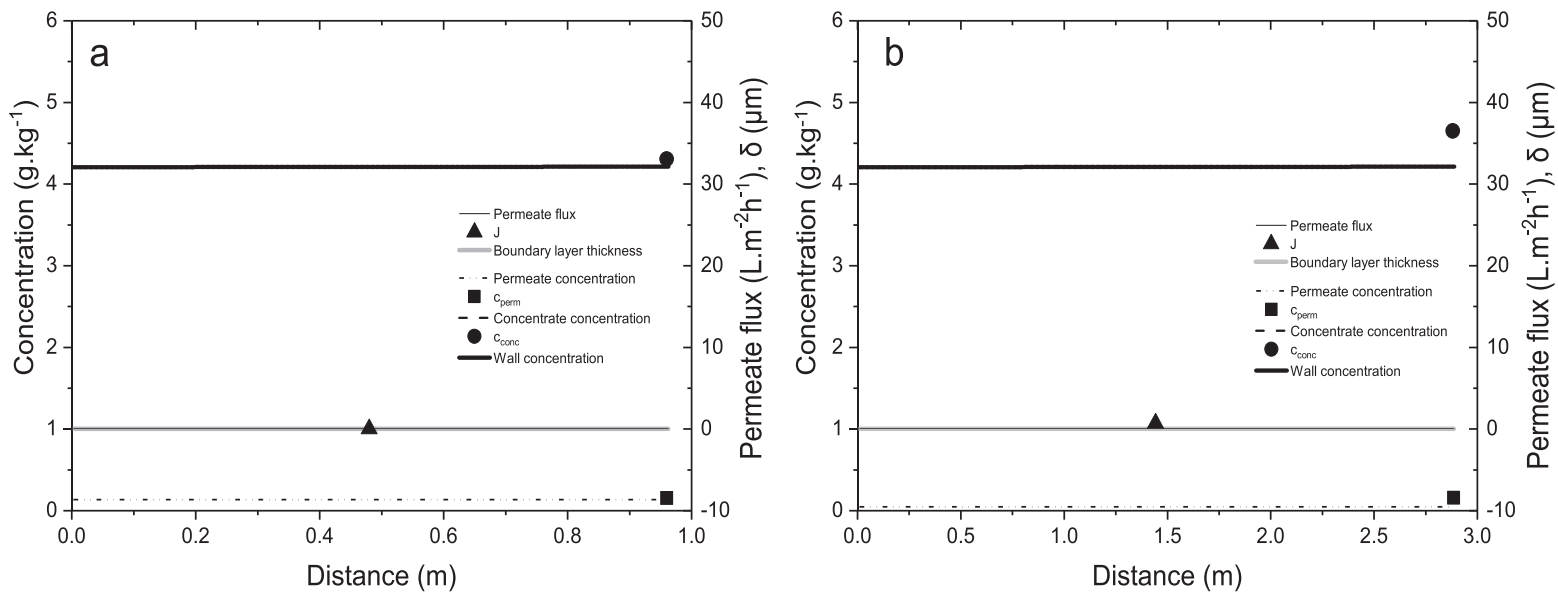

Fig. 13. Trend of the wall, permeate and concentrate concentration, permeate flux and boundary layer thickness over the length of the module for (a) $1 * B W 30-4040$ module and (b) $3 *$ BW30-2540 configurations at the medium energy level.
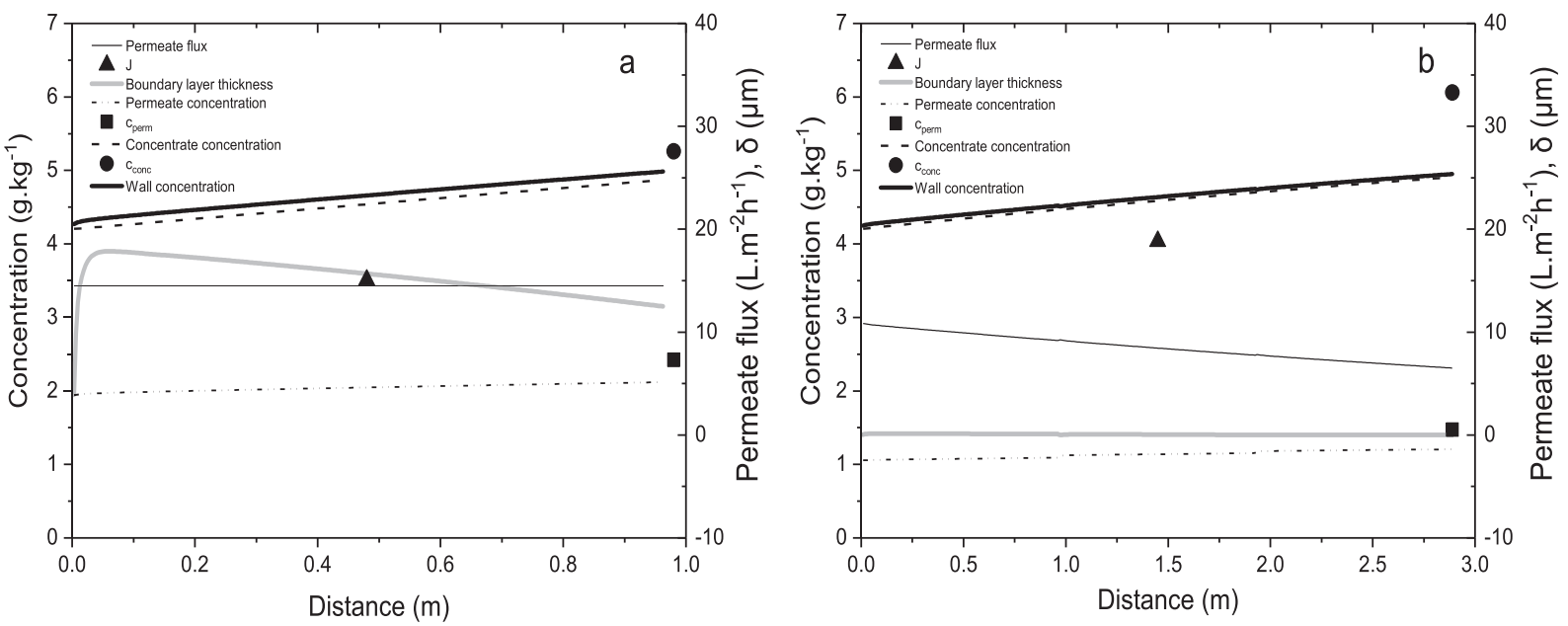

Fig. 14. Trend of the wall, permeate and concentrate concentration, permeate flux and boundary layer thickness over the length of the module for (a) 1 * NF2704040 module and (b) $3 *$ NF270-2540 configurations at the medium energy level.

lower than the experimental value. Hence both configurations produce a permeate quality with almost the same concentration. At approxi mately the same permeate flux, $c_{p}$ depends linearly on $c_{w}$ (Eq. (9)) therefore the small difference can be attributed to the somewhat lower $\mathrm{c}_{\mathrm{w}}$ in this configuration due to the insignificant concentration polar ization observed.

Similarly, Fig. 12 shows the results of the two configurations equipped with the NF270 membrane. A higher permeate flux was 
expected for this membrane (loose membrane) and the simulation confirmed the experimental results. As expected the permeate flux de creases over the length of the module and in this case the decrease is more pronounced than with the tighter BW30 membrane.

Fig. 12(a) illustrates that all the parameters (boundary layer thick ness, permeate flux, wall concentration and permeate concentration) increase in the first part of the 4" module (for the first $7 \mathrm{~cm}$ ) and then the trend is linear over the length of the module, increasing for the wall and concentrate concentrations, decreasing for boundary layer thick ness and permeate flux.

As expected, the permeate quality of NF270 is lower than the BW30. The permeate concentration slightly increases over the length of the module, for the $4^{\prime \prime}$ module $\mathrm{c}_{\mathrm{p}}$ increases from $1.2 \mathrm{~g} \mathrm{~kg}^{-1}$ to $1.4 \mathrm{~g} \mathrm{~kg}^{-1}$, which is about $17 \%$ less than the measured value.

The results of the $3 * 2.5^{\prime \prime}$ configuration in Fig. 12(b) indicate again a much reduced boundary layer thickness, even though for the more open membrane a boundary layer is clearly visible. The wall con centration is similar, while the permeate concentration is noticeably lower, it increases from $0.7 \mathrm{~g} \mathrm{~kg}^{-1}$ to $1 \mathrm{~g} \mathrm{~kg}^{-1}$ over the length of the module, with a relative deviation from the measured value of $27 \%$.

Overall the simulation results are in good agreement with the ex perimental data at the high energy level.

\subsection{Medium energy level ('light cloud period' irradiance $360 \mathrm{~W} / \mathrm{m}^{2}$ )}

Analogue to the previous section, Figs. 13 and 14 show the simu lated values for the membrane module BW30 and NF270 membranes, respectively. Fig. 13(a) illustrates the results of the 1 * BW30 4040 and (b) the $3 *$ BW30 2540 configurations at the medium energy level $\left(0.36 \mathrm{kWh}^{-1}, 330360 \mathrm{Lh}^{-1}\right.$ and 2.83 .9 bar).

The feed concentration was constant over the length of the modules in both configurations. Indeed, at this energy level, the feed pressure was about 2.89 bar, and hence too low to overcome the osmotic pres sure of 2.88 bar of this water. In consequence, no water permeation occurred. The permeate flux is constant and equal to $0.07 \mathrm{~L} \mathrm{~m}^{-2} \mathrm{~h}^{-1}$ for both membranes and the permeate quality decreased significantly.

For the NF270 membrane (Fig. 14) permeation is still observed at this energy level, both experimentally and in the simulation. The sig nificant decrease of permeate flux compared to the high energy level is evident. Flux is about $14 \mathrm{~L} \mathrm{~m}^{-2} \mathrm{~h}^{-1}$ for the $1 * 4^{\prime \prime}$ module with a de viation of $18 \%$ from the experimental values, while for the $3^{*} 2.5^{\prime \prime}$ configuration $\mathrm{J}$ reduces from about $11 \mathrm{~L} \mathrm{~m}^{-2} \mathrm{~h}^{-1}$ to $6.5 \mathrm{~L} \mathrm{~m}^{-2} \mathrm{~h}^{-1}$ with a significant deviation from the experimental value.

The permeate quality of is of course very low given the conditions and about 20 times the permeate concentration of the BW30 mem brane. Indeed, for this membrane, the permeate flux was not zero and therefore permeate with a higher concentration was collected in both configurations. It should be noted here that the simplifications in the model deviate from reality in that NF270 will remove TDS, but not $\mathrm{NaCl}$ per se. In this sense much further species dependent modelling work is required. Nevertheless, despite these simplifications and limitations that persist in this model, the agreement between model and experi ment is good.

\subsection{Lowest energy level ('heavy cloud period' irradiance $190 \mathrm{~W} / \mathrm{m}^{2}$ )}

At the lowest energy level (170 $220 \mathrm{~L} / \mathrm{h}$ and $11.5 \mathrm{bar}$ ), the feed pressure was well below the osmotic pressure. A negative flux for the module 2.5"BW30 and 4" NF270 was obtained, while for the other two modules the simulation was interrupted because of numerical in stabilities. One of the main assumptions of the model was a positive flux and this assumption is no longer valid at lower energy levels. The ex perimental observations at these conditions are indeed a negative permeate flux which warrants further investigation.

\section{Conclusions}

The model developed in this research is able to determine the wall concentration and the boundary layer thickness over the length of the module using experimental data that was obtained during experiments with fluctuating energy, namely at varying solar irradiance settings. This data was summarized for this work to three energy levels that are significant points in such fluctuation.

The simulation results obtained are in very good agreement with the experimental data. Although the two configurations result in different wall concentrations, no difference in the water quality between the two systems equipped with tighter BW30 membrane was observed. Regarding the more open NF270 membrane there is a difference in flux and permeate quality between the two configurations. Both flux and permeate concentration are significantly higher in the $1 * 4$ " module configuration.

Further investigations on the possibility to modify the geometry and the boundary conditions of the model are required in order to in corporate the pressure drop and the solute mass flux, differentiating between different salt species, on both sides of the membrane.

\section{Acknowledgements}

Dr Junjie Shen and Prof Bryce Richards are acknowledged for their participation in the field work that has provided the experimental data for this modeling project. Dow Chemicals company is thanked for providing membranes for the experimental work and helpful discus sions about module design. The Helmholtz Association is thanked for project funding for IFG MT through the Recruitment Initiative for A.S.

\section{References}

[1] A. Schäfer, A. Broeckmann, B. Richards, Renewable energy powered membrane technology. 1. Development and characterization of a photovoltaic hybrid membrane system, Environ. Sci. Technol. 41 (2007) 998-1003.

[2] W.J. Cosgrove, The United Nations World Water Development Report-No 4-The Dynamics of Global Water Futures: Driving Forces 2011-2050, UNESCO, 2012.

[3] C. Charcosset, A review of membrane processes and renewable energies for desalination, Desalination 245 (2009) 214-231.

[4] P. Malek, J. Ortiz, H. Schulte-Herbrüggen, Decentralized desalination of brackish water using an electrodialysis system directly powered by wind energy, Desalination 377 (2016) 54-64.

[5] G. Fimbres-Weihs, D. Wiley, Numerical study of mass transfer in three-dimensional spacer-filled narrow channels with steady flow, J. Membr. Sci. 306 (2007) 228-243.

[6] G. Fimbres-Weihs, D. Wiley, D.F. Fletcher, Unsteady flows with mass transfer in narrow zigzag spacer-filled channels: a numerical study, Ind. Eng. Chem. Res. 45 (2006) 6594-6603.

[7] T. Melin, R. Rautenbach, Membranverfahren: Grundlagen der Modul-und Anlagenauslegung, Springer-Verlag, 2007.

[8] J. Shen, G. Mkongo, G. Abbt-Braun, S.L. Ceppi, B.S. Richards, A.I. Schäfer, Renewable energy powered membrane technology: fluoride removal in a rural community in northern Tanzania, Sep. Purif. Technol. 149 (2015) 349-361.

[9] A. Schäfer, A. Broeckmann, B. Richards, Renewable energy powered membrane technology. 1. Development and characterization of a photovoltaic hybrid membrane system; 2007.

[10] M. Gruber, C. Johnson, C. Tang, M.H. Jensen, L. Yde, C. Hélix-Nielsen, Computational fluid dynamics simulations of flow and concentration polarization in forward osmosis membrane systems, J. Membr. Sci. 379 (2011) 488-495.

[11] B. Richards, D. Capão, A. Schäfer, Renewable energy powered membrane technology. 2. The effect of energy fluctuations on performance of a photovoltaic hybrid membrane system, Environ. Sci. Technol. 42 (2008) 4563-4569.

[12] J. Shen, A. Jeihanipour, B.S. Richards, A.I. Schäfer, Renewable energy powered membrane technology: experimental investigation of system performance with variable module size and fluctuating energy, Sep. Purif. Technol. (2018), https:// doi.org/10.1016/j.seppur.2019.03.004 (in press).

[13] S. Kim, E.M. Hoek, Modeling concentration polarization in reverse osmosis processes, Desalination 186 (2005) 111-128.

[14] V.t. Geraldes, V. Semião, M.N. DE Pinho, Flow and mass transfer modelling of nanofiltration, J. Membr. Sci. 191 (2001) 109-128.

[15] C. Rodrigues, P. Garcia-Algado, V. Semião, M.N. de Pinho, V. Geraldes, Concentration boundary layer visualization in nanofiltration by holographic interferometry with light deflection correction, J. Membr. Sci. 447 (2013) 306-314.

[16] S. Wardeh, H. Morvan, CFD simulations of flow and concentration polarization in spacer-filled channels for application to water desalination, Chem. Eng. Res. Des. 86 (2008) 1107-1116.

[17] M.F. Gruber, C.J. Johnson, C. Tang, M.H. Jensen, L. Yde, C. Hélix-Nielsen, 
Validation and analysis of forward osmosis CFD model in complex 3D geometries, Membranes 2 (2012) 764-782.

[18] G. Keir, V. Jegatheesan, A review of computational fluid dynamics applications in pressure-driven membrane filtration, Rev. Environ. Sci. Bio/Technol. 13 (2014) 183-201.

[19] J.L.C. Santos, V. Geraldes, S. Velizarov, J.G. Crespo, Investigation of flow patterns and mass transfer in membrane module channels filled with flow-aligned spacers using computational fluid dynamics (CFD), J. Membr. Sci. 305 (2007) 103-117.

[20] M.F. Gruber, U. Aslak, C. Hélix-Nielsen, Open-source CFD model for optimization of forward osmosis and reverse osmosis membrane modules, Sep. Purif. Technol. 158 (2016) 183-192.

[21] B. Gu, C.S. Adjiman, X.Y. Xu, The effect of feed spacer geometry on membrane performance and concentration polarisation based on 3D CFD simulations, J. Membr. Sci. 527 (2017) 78-91.

[22] J. Schwinge, D. Wiley, D. Fletcher, Simulation of the flow around spacer filaments between narrow channel walls. 1 Hydrodynamics, Ind. Eng. Chem. Res. 41 (2002) 2977-2987.

[23] G. Fimbres-Weihs, D. Wiley, Review of 3D CFD modeling of flow and mass transfer in narrow spacer-filled channels in membrane modules, Chem. Eng. Process. Process Intensif. 49 (2010) 759-781.

[24] E. Dimitriou, P. Boutikos, E.S. Mohamed, S. Koziel, G. Papadakis, Theoretical performance prediction of a reverse osmosis desalination membrane element under variable operating conditions, Desalination 419 (2017) 70-78.

[25] J. Shen, B.S. Richards, A.I. Schäfer, Renewable energy powered membrane technology: Case study of St. Dorcas borehole in Tanzania demonstrating fluoride removal via nanofiltration/reverse osmosis, Sep. Purif. Technol. 170 (2016) 445-452.

[26] Y. Wang, W. He, H. Zhu, Computational fluid dynamics (CFD) based modelling of osmotic energy generation using pressure retarded osmosis (PRO), Desalination 389 (2016) 98-107.

[27] D. Fletcher, D. Wiley, A computational fluids dynamics study of buoyancy effects in reverse osmosis, J. Membr. Sci. 245 (2004) 175-181.

[28] D.E. Wiley, D.F. Fletcher, Techniques for computational fluid dynamics modelling of flow in membrane channels, J. Membr. Sci. 211 (2003) 127-137.

[29] J. Wijmans, R. Baker, The solution-diffusion model: a review, J. Membr. Sci. 107 (1995) 1-21.

[30] U. Merten, Desalination by reverse osmosis, MIT Press (1966).
[31] M. Soltanieh, W.N. GILL', Review of reverse osmosis membranes and transport models, Chem. Eng. Commun. 12 (1981) 279-363.

[32] D.R. Paul, Reformulation of the solution-diffusion theory of reverse osmosis, J. Membr. Sci. 241 (2004) 371-386.

[33] A. Poisson, A. Papaud, Diffusion coefficients of major ions in seawater, Mar. Chem. 13 (1983) 265-280.

[34] J. Shen, A.I. Schäfer, Factors affecting fluoride and natural organic matter (NOM) removal from natural waters in Tanzania by nanofiltration/reverse osmosis, Sci. Total Environ. 527 (2015) 520-529.

[35] T. Singh, Y. Kalra, G. Hillman, Effects of pulpwood harvesting on the quality of stream waters of forest catchments representing a large area in Western Alberta, Canada, Effects of man on the interface ûf the hydrologioal oyole with the physical environment; 1974 p. 21.

[36] T. Singh, Y. Kalra, Specific conductance method for in situ estimation of total dissolved solids, J.-Am. Water Works Assoc. 67 (1975) 99-100.

[37] J. Schwinge, D. Wiley, D. Fletcher, Simulation of unsteady flow and vortex shedding for narrow spacer-filled channels, Ind. Eng. Chem. Res. 42 (2003) 4962-4977.

[38] S.G. Chatterjee, G. Belfort, Fluid flow in an idealized spiral wound membrane module, J. Membr. Sci. 28 (1986) 191-208.

[39] C. Geuzaine, J.F. Remacle, Gmsh: A 3-D finite element mesh generator with built-in pre-and post-processing facilities, Int. J. Numer. Meth. Eng. 79 (2009) 1309-1331.

[40] M. Gaedtke, Bestimmung der Leistungsfähigkeit bei fluktuierendem Energieeintrag mithilfe der numerischen Strömungssimulazion (CFD), Masterarbeit, Karlsruhe Institute of Technologie (KIT), 2016.

[41] T. Holzmann, Mathematics, Numerics, Derivations and OpenFOAM ${ }^{\oplus}$, in, Holzmann CFD; 2016.

[42] J. Ferziger, M. Peric, Computational Methods for Fluid Dynamics, Springer, Berlin Heidelberg, 2001.

[43] R. Courant, K. Friedrichs, H. Lewy, Über die partiellen Differenzengleichungen der mathematischen Physik, Mathematische annalen 100 (1928) 32-74.

[44] S. Yüksel, N. Kabay, M. Yüksel, Removal of bisphenol A (BPA) from water by various nanofiltration (NF) and reverse osmosis (RO) membranes, J. Hazard. Mater. 263 (2013) 307-310.

[45] A. Tressaud, Fluorine and the environment: agrochemicals, archaeology, green chemistry and water, Elsevier, 2006. 
Karlsruher Institut für Technologie

\section{Repository KITopen}

Dies ist ein Postprint/begutachtetes Manuskript.

\section{Empfohlene Zitierung:}

Onorato, C.; Gaedtke, M.; Kespe, M.; Nirschl, H.; Schäfer, A. I.

Renewable energy powered membrane technology: Computational fluid dynamics evaluation of system performance with variable module size and fluctuating energy. 2019. Separation and purification technology, 220.

doi: $10.5445 / I R / 1000094430$

Zitierung der Originalveröffentlichung:

Onorato, C.; Gaedtke, M.; Kespe, M.; Nirschl, H.; Schäfer, A. I.

Renewable energy powered membrane technology: Computational fluid dynamics evaluation of system performance with variable module size and fluctuating energy.

2019. Separation and purification technology, 220, 206-216.

doi: 10.1016/j.seppur.2019.02.041 